\title{
TINJAUAN TENTANG PENDIRIAN KEDATON TERNATE
}

Oleh: Syamsir Alam,

\section{Pendahuluan}

Pada bulan Oktober 1983 yang lalu dalam suatu kunjungan ke Maluku telah dikunjungi pula pulau-pulau Ternate. Pulau ini telah dikenal sejak beberapa abad yang lalu karena di pulau ini pernah terdapat sebuah kerajaan yang bernama Kerajaan Ternate. Kerajaan ini didirikan kira-kira pada abad ke 13 dan mengalami keruntuhan pada abad ke 20. Raja Ternate yang pertama adalah Cico alias Mashur Malamo, sedang. kan sultan yang terakhir bernama Iskandar Muhammad Jabir Syah. Selama kerajaan tersebut berdiri terdapat 20 orang raja dan 26 Sultan yang pernah memerintah.

Walaupun saat ini pemeerintahan kerajaan Ternate telah dihapuskan. tetapi sisa-sisa peninggalan kerajaan tersebut masih dapat disaksikan di kota Ternate. Salah satu peninggalan yang cukup penting adalah sebuah kedaton (istana) yanǵ terletak di tengah kota Ternate. Pada saat ini kedaton tersebut tidak berfungsi lagi sebagai istana kerajaan, tetapı telah dijadikan museum.

Menurut keterangan Muhammad Rajab (guru SMA Negeri Ternate), kedaton yang terletak di tengah kota Ternate tersebut adalah kedaton yang ke tiga atau kedaton yang terakhir dari kerajaan Ternate. V.I. Van de Wall melukiskan kedaton yang ke tiga sebagai kedaton yang paling megah dan indah. Bentuk dan gaya kedaton meniru rumah peristirahatan 
orang-orng Eropa yang tinggal di Indonesia di masa itu. Kedaton ini terletak di pinggir pantai dan didirikan di lereng sebuah bukit sehingga bagian belakang rata dengan bagian daratan, sedangkan bagian depan beserta beranda atau balkon merupakan bagian bangunan yang disangga pilar-pilar batu (Van de Wall, 1923: 138).

Pada beranda atau balkon, tepatnya di atas pintu yang menghubungkan beranda dengan ruang tengah kedaton, terdapat batu peringatan atau prasasti. Menurut keterangan Muhammad Rajab, prasasti tersebut isinya menerangkan tentang pendirian kedaton tersebut. Melihat bentuk tulisan prasasti ini, dapat diperkirakan bahwa kedaton tersebut didirikan oleh seorang penguasa kerajaan Ternate setelah agama Islam masuk di Ternate.

Tulisan ini hanya terbatas pada pembicaraan tentang pendirian kedaton Ternate saja. Walaupun demikian diharapkan karangan ini dapat digunakan sebagai pengantar untuk menuju ke arah penelitian lebih lanjut.

\section{Gelar Sultan}

Tempat kediaman raja-raja beserta kerabatnya adalah keraton atau istana. Bagi kerajaan Ternate, tempat kediaman raja atau sultan disebut kedaton. Dari keraton atau kedaton itulah raja menjalankan pemerintahan dan kekuasaannya.

Gelar raja atau maharaja pada zaman pertumbuhan dan perkembangan Islam di Indonesia masih digunakan di samping gelar sultan yang muncul karena pengaruh Islam. Pemakaian gelar sultan yang pertama kali di Indonesia digunakan oleh Sultan Malik As Saleh seperti diketahui dari nisan kuburnya yang berangka tahun $696 \mathrm{H}$ (1297 M) yang terletak di Gampong Samodra, bekas kerajaan Samodra Pasai, Kabupaten Lhoksumawe, Propinsi Daerah Istimewa Aceh (Uka Tjandrasasmita, 1975: 176). Setelah itu gelar sultan juga digunakan oleh pimpinan kerajaan Islam lainnya di Indonesia, seperti Sultan Ageng Tirtayasa dari Banten,Sultan Agung dari Mataram, dan Sultan Hasanudin dari Makasar. 
Mengenai kedatangan Islam di Indonesia, khususnya kedatangannya di Indonesia Timur yaitu Maluku, diperkirakan sejak abad 14 Masehi agama Islam telah datang ke daerah tersebut (Uka Tjandrasasmita; 1975, 95). Hal ini dibuktikan dari tradisi masyarakat setempat.

\section{Batu peringatan atau prasasti kedaton Ternate}

Batu peringatan atau prasasti yang terdapat di kedaton Ternate menempel pada dinding dan dibuat dari marmer (B. Soelarto, tanpa tahun; 216). Prasasti ini berbentuk agak bulat dengan gerigi-gerigi di pinggirnya. Pada bagian atas prasasti terdapat tanda palang (+). Prasasti ini bertuliskan huruf Arab dengan bahasa Arab dan bahasa Melayu. Tulisan yang terdapat pada prasasti ini berjumlah dua belas baris, sepuluh baris berbahasa Arab dan dua baris lagi berbahasa Melayu. Antara baris ke sepuluh dan baris ke sebelas terdapat satu kata dalam bahasa melayu yaitu "Tamat".

Dengan bantuan dua orang teman (Dra. Nena Mansur dan Drs. Mansur Fakih), ke dua alumni IAIN telah diusahakan untuk mengalihtuliskan prasasti tersebut dari tulisan Arab menjadi tulisan Latin. Bunyi prasasti tersebut selengkapnya adalah sebagai berikut:

1. baris 1: Wa kaannahul faragho min darojatil a'liyatir rafi'ah Maulanas Shulthoona;

2. baris 2: Sayyidul biladi sirajal a'luwul mulki Iskandariyiin;

3. baris 3: Wa huwa,khairussholihiina Muhammad A'li ibnus Shulton Arrahman;

4. baris 4: Maal waziiri fi zamaanil mawafiqi ila ahadihi kaptin;

5. baris 5: Kamaras ismuhu maknasay fil musyawarati wa fa'alru;

6. baris 6: Bil qudratillahi hazal baitilmulki syarfi a'lal biladi Ternati;

7. baris 7: Min fawqoljabalul maa'i wahadana lahu khairul waaritsi;

8. baris 8: A'la kulli muzlati wa nukiro lahu salaaminal mutaakhirinal afa haaza abada;

9. baris 9: Wa salamatu walau kaannahu laminal mulki ma lisa hasal baiti wallahu; 
10. baris 10 : Warasuulahu walam yajid salamatu lahu hatta ilaa yaumil qiyamati;

11. baris 11: Permulaan tiga puluh hari tatkala ini rumah dari pada bulan Zulkadah harinya

12. baris 12: Ahad seribu dua ratus dua puluh delapan (1228) tahun Hijriah.

\section{Tokoh Pendiri Kedaton Ternate}

Dalam pendahuluan karangan ini telah disebutkan bahwa kerajaan Ternate didirikan pada abad 13 dengan raja pertama bernama Cico alias Mashur Malamo. la memerintah dari tahun 1257-1277 M yaitu di daerah Faramadiahi. Di kota Faramadiahi inilah kedaton pertama kerajaan Ternate didirikan. Letak kota Faramadiahi kira-kira sebelas kilometer ke arah selatan kota Ternate sekarang, naik ke arah gunung kira-kira empat setengah kilometer, yaitu di kampung Kastela. Selain raja Cico masih terdapat lagi raja-raja yang memerintah di kerajaan Ternate sebanyak sembilan belas orang.

Raja Ternate yang ke duabelas, Molomateya yang memerintah dari tahun 1350-1357 M bersahabat karib dengan orang Arab yang memberikan petunjuk bagaimana membuat kapal. Pada masa pemerintahan raja Ternate yang kesembilan belas, yaitu raja Marhum yang memerintah dari tahun 1465-1486 M, datanglah seorang datu dari Jawa bernama Maulana Husayn yang mengajarkan mengenai pemahaman huruf Arab dalam Qur'an. Raja Marhum sangat tertarik, sehingga Maulana Hasayn diminta mengajarkan menulis huruf yang indah itu. Kemungkinan saat itu merupakan titik awal perkembangan seni menulis huruf Arab di Ternate. Selanjutnya raja yang dianggap benar-benar memeluk agama Islam adalah raja Ternate yang kedua puluh yaitu raja Zainal Abidin yang memerintah tahun 1486-1500 M. Raja Zainal Abidin ketika sedang berada di Jawa yaitu sewaktu mempelajari agama Islam di Madrasah Giri dikenal sebagai raja Bulawa yang berarti Raja Cengkeh. Julukan tersebut muncul karena Raja Zainal Abidin membawa cengkeh untuk persembahan. Sekembalinya dari Jawa, Raja Zainal Abi- 
din membawa mubaligh yang bernama Tuhubahahul. Raja Zainal Abidin adalah orang terakhir yang menggunakan gelar raja di kerajaan Ternate. Setelah itu gelar Sultan digunakan di kerajaan Ternate. Hal ini merupakan suatu pertanda bahwa kerajaan Ternate adalah kerajaan Islam. Berdasarkan berita Tom Pires raja Ternate yang telah memeluk agama islam adalah Sultan Bem Acorala, sedangkan yang memerintah sebelumnya tetap bergelar raja (Uka Tjandrasasmita, 1975; 257). Nama lain dari Sultan Bem Acorala adalah Sultan Binaracola (pendapat Barbarosa) atau Abuleis (pendapat Pigafetta). Nama-nama tersebut sama dengan nama yang terdapat dalam silsilah kerajaan Ternate yaitu Sultan Bajanulloh. Sultan Bajanulloh memerintah dari tahun 1500-1522 M.

Sejak abad ke 16 Kerajaan Ternate memasuki sejarah baru dalam hubungannya dengan bangsa-bangsa Eropa. Bangsa Portugis adalah bangsa asing pertama datang ke Ternate. Pada mulanya bangsa tersebut berdagang, akan tetapi lama kelamaan menanamkan kekuasaannya, Portugis mendapatkan ijin dari Sultan Ternate untuk mendirikan benteng-benteng. Setelah Portugis merasa kuat, maka usaha penyebaran agama Nasrani atau usaha menasranikan sultan dan keluarganya penduduk yang sebagian besar telah beragama Islam. Penguasa Portugis de'Ataido berpendapat bahwa jika sultan dan keluarganya telah dinasranikan maka dengan sendirinya mereka akan patuh kepada penguasa Portugis. Ini Portugis dapat menguasai kerajaan Ternate.

Pada tahun 1535 de'Ataido menculik sultan Tabriji dan mengasing. kannya ke Goa. Sebagai penggantinya adalah Sultan Hairun. Ia memerintah dari tahun, 1538-1565 M. Sultan Hairun mati dibunuh secara biadab oleh pasukan Portugis dipimpin oleh Mosquito.

Kemudian Sultan Hairun digantikan oleh puteranya yang bernama Sultan Baabulah. la memerintah dari tahun 1565-1583 M pada masa pemerintahan Sultan Baabulah inilah bangsa Portugis dapat diusir dari Ternate dengan ditandainya dihancurkannya benteng Portugis Santo Paolo. Sultan Baabulah digantikan oleh Sultan Saidi Barkati. la memerintah dari tahun 1583-1610. Pada masa pemerintahan Sultan Saidi Barkati, muncullah bangsa Belanda untuk pertamakalinya di Ternate. 
Orang-orang Belanda pertama menginjakkan di Ternate di bawah pimpinan Wiybrand Van Waerwijk, mendarat atau berlabuh dengan kapal Amsterdam dan Utrech pada tanggal 22 Mei 1599 (Van de Wall, 1923: 138). Pada masa pemerintahan Sultan Saidi Barkati dimulai usaha penulisan sejarah dengan menggunakan huruf Arab Melayu.

Setelah mengetahui bahwa bangsa Portugis telah lenyap kekuasaannya dari Ternate, bangsa Spanyol berhasil menanamkan kekuasaannya di Ternate. Akan tetapi bangsa Spanyol berhasil diusir dari Ternate pada masa pemerintahan Sultan Muzaffar. Sultan ini memerintah dari tahun 1610-1627 M. Pada waktu pemerintah Sultan Muzaffar ibukota kesultanan Ternate dipindahkan ke pantai barat, yaitu dengan ibukota Melayu (Soelarto, tanpa tahun: 31). Menurut keterangan Muhammad Rajab kedaton Ternate yang ke dua ini terletak di kampung Limau Jore-Jore. Kampung ini masih termasuk dalam kota Ternate sekarang.

Pada awal kedatangan Belanda di Ternate, mereka mengakui kesultanan Ternate. Lama kelamaan kesultanan Ternate berada di bawah kekuasaan Kompeni. Sejak tahun 1683 kesultanan Ternate tidak lagi sebagai negara yang berdaulat penuh dan dipaksa menjadi negara Vasal (Departemen Pendidikan dan Kebudayaan, 1978 : 72).

Selain bangsa Portugis, Spanyol dan Belanda, kesultanan Ternate juga mengenal bangsa Inggris dalam hubungannya dengan bangsa Eropa. Pada awal abad ke 19 terjadi peristiwa bersejarah di Ternate, yaitu Gubernùr Willem Yacob Cranssen menentang penyerahan kekuasaan kompeni kepada Inggris dan meminta Sultan Ternate untuk menyerahkan penduduk guna melawan kedatangan tentara Inggris. Akan tetapi permintaan ini tidak dipenuhi Sultan Ternate, sehingga Kompeni terpaksa menyerahkan kekuasaannya kepada Inggris. Dalam sejarah Nasional Indonesia disebutkan bahwa Inggris pernah berkuasa di Indonesia dari tahun 1811 - 1816. Adapun penguasa Inggris pada waktu itu adalah Letnan Jendral Thomas Stamford Raffles. Administrasi pemerintahan Inggris di Indonesia pada waktu itu dibagi dalam empat unit, antara lain di Maluku dengan seorang residen Jendral yaitu Bryant Martin. Sedangkan di Ternate ditugaskan seorang residen bernama W.G. Mackansie. 
Residen tersebut bertugas dua kali di Ternate, yaitu pada tahun-tahun 1813 dan 1816. Pada masa pemerintahan Inggris yang singkat, Ternate yang berkuasa adalah Sultan Muhammad Ali (1807 - 1822). Sultan Muhammad Ali menjalin persahabatan dengan residen Mackansie dalam keadaan damai itu didirikanlah kedaton Ternate yang ke tiga atau terakhir (Van de Wall, 1923:138). Selain itu, prasasti kedaton Ternate pada baris ke tiga menyebut nama Muhammad Ali. Maka jelas bahwa kedaton Ternate yang ketiga atau terakhir didirikan oleh Sultan Muham. mad Ali. Pembangunan dimulai pada hari Ahad tanggal 30 bulan Zulkaidah tahun $1228 \mathrm{H}$ (Minggu tanggal 24 November $1813 \mathrm{M}$ ).

Selama masa pemerintahan Inggris di Maluku, keadaan tidak berbeda dengan masa penjajahan Belanda, meskipun terdapat beberapa perubahan, misalnya pengurangan wajib hongi dan pajak (Departemen Pendidikan dan Kebudayaan, 1978: 73). Setelah kekuasaan kembali ke tangan Inggris dari Belanda, status kesultanan Ternate diturunkan setingkat. yaitu sama dengan Karesidenan. Penguasanya adalah seorang residen Belanda sebagai penguasa tertinggi di Ternate.

Sultan Ternate yang terakhir adalahı Iskandar Muhammad Jabir Syah. Pada masa pemerintahannya Indonesia mengalami kemerdekaan. Selanjutnya kesultanan Ternate menjadi daerah Karesidenan dengan sultan menjabat sebagai residen. Pada perkembangan lebih lanjut, Ternate menjadi daerah Kabupaten dengan status daerah Tingkat II Maluku Utara. Sultan Iskandar Muhammad Jabir Syah memerintah sejak tahun 1929 dan wafat tahun 1974. Beliau adalah sultan terakhir dari kerajaan Ternate.

\section{Penutup}

Sebagai penutup dapat dikemukakan beberapa hal sebagai berikut:

1. Kerajaan Ternate pernah mengalami perpindahan ibu kota kerajaan dan memiliki tiga buah kedaton. Kedaton pertama terletak di kampung Kastela yang didirikan pada masa Raja Cico (Mashur Malamo). Kedaton ini berdiri sekitar 1257-1610 M. Kedaton kedua terletak di kampung Limau Jore-Jore dan didirikan oleh Sultan Muzaffar. 
Kedaton ini digunakan sekitar $1610-1813$. Sedangkan kedaton terakhir terletak di kota Ternate sekarang, yang didirikan oleh Sultan Muhammad Ali. Pendiriannya dimulai pada hari Minggu, 24 Novem. ber 1813.

2. Para pengusaha kerajaan Ternate sejak didirikan tahun 1257 sampai tahun 1500 memakai gelar raja, sedangkan setelah tahun 1500 digunakan gelar Sultan. Pergantian gelar raja dengan sultan merupakan akibat masuknya pengaruh Islam di kerajaan Ternate.

Demikian beberapa hal yang dapat diungkapkan tentang pendirian kedaton Ternate. Diharapkan tulisan ini dapat bermanfaat bagi penelitian selanjutnya.

\section{Lampiran}

\section{NAMA RAJA-RAJA DAN SULTAN-SULTAN KERAJAAN TERNATE}

1. Raja Tjitjo alias Mansur Malamo

$1257-1277$

2. Raja Poit alias Samman

$1277-1284$

3. Raja Siale

$1284-1294$

4. Raja Kalebata alias Baguna

$1294-1304$

5. Raja Komala alias Ngara Malamo

$1304-1317$

6. Raja Sjafiuddin alias Patjaranca Malamo

$1317-1322$

7. Raja Sida Arif Malamo

$1322-1331$

8. Raja Padji Malamo

9. Raja Tolu Malamo

$1331-1332$

10. Raja Syah Alam

$1332-1343$

11. Raja Bohejat alias Kiye Mabidji I

$1343-1347$

12. Raja Ngolo ma Tjahaja (Molomateya)

$1347-135()$

13. Raja Momole

14. Raja Gapi Malamo

$\left.1357-135^{9}\right)$

15. Raja Gapi Baguna I

$1359-1372$

16. Raja Komala Pulu

$1372-1377$

17. Raja Gisi

$1377-$ ?

18. Raja Gapi Baguna II 
19. Raja Marhum

$1465-1486$

20. Raja Zainal Abidin

$1486-1500$

21. Sultan Bajanullah

$1500-1522$

22. Sultan Dejal

$1522-1533$

23. Sultan Bohejat II

$1533-1537$

24. Sultan Tabridji

$1537-1538$

25. Sultan Chaerun alias Djamil

$1538-1565$

26. Sultan Babullah

$1565-1583$

27. Sultan Sahit (walinya Saidi Barkati)

$1583-1606$

Sultan Saidi Barkati

$1606-1610$

28. Sultan Mudzaffar

$1610-1627$

29. Sultarı Hamzah

$1627-1648$

30. Sultan Mandar Sjah

$1648-1672$

31. Sultan Said Fatahullah alias Katjiri Sibori

$1672-1690$

32. Sultan Amir Zulkarnain alias Katjili Toloko

$1690-1724$

33. Sultan Alaudin Mansjur

34. Sultan Amir Iskandar Sjahmardan

$1724-$ ?

35. Sultan Kalamata

36. Sultan Harun Sjah

37. Sultan Djou Pulang Gapi

38. Sultan Muhammad Jasin

39. Sultan Muhammad Ali

$?-?$

? -1807

40. Sultan Muhammad Safiuddin alias Sultan Sarmole 1822 - 1823

41. Sultan Muhammad Zen alias Djain

42. Sultan Muhammad Arsad

43. Sultan Aijanhar Sjah

44. Sultan Haji Muhammad Usman Ilham

$1823-1859$

45. Sultan Haji Muhammad Usman

$1859-$ ?

46. Sultan Iskandar Muh. Djabir Sjah

$?-1900$

$1900-1902$

$1902-1929$

$1929-$ ? 


\section{Daftar bacaan}

Departemen Pendidikan dan Kebudayaan. 1978. Sejarah Daerah Maluku. Jakarta: PN. Balai Pustaka.

Direktorat Jenderal Kebudayaan. 1972. Bengkulu dipandang dari sudut Geografi/ Sejarah dan Kebudayaan. Jakarta: Proyek Inventarisasi dan Dokumentasi Kebudayaan Nasional.

Museum Nasional, Direktorat Jenderal Kebudayaan. 1982. Prasasti Sebagai Sumber Sejarah. Jakarta.

Museum Negeri Siwalima. 1982. Dari Foramadiahi ke Limau Jore-Jore. Ambon.

Sodrie, Adhmad Cholid. 1983. Naskah Penyerta dalam Al-Quran Kuno dari Temate. Jakarta: Pusat Penelitian Arkeologi Nasional.

Soelarto, B. tanpa tahun. Sekitar Tradisi Temate. Jakarta: Proyek Pengembangan Media Kebudayaan.

Tjandrasasmita, Uka. 1975. Sejarah Nasional Indonesia. Jilid III Jakarta: Departemen Pendidikan dan Kebudayaan.

Van de Wall, V.I. 1923. Het Museum Kedaton Van Temate dalam Dudheidkundig Verslag, Vierde Kwartaal. Jakarta. 